\title{
On the Subject of Michel Foucault's Human Science Archeology Period
}

\author{
Hongjia Li \\ Instruction Center for College Students' Entrepreneurship and Employment, Mudanjiang Normal University, \\ Mudanjiang, China
}

\begin{abstract}
Foucault, in his human science archaeology period, carried out researches and analyses on the historical conditions and specific rules of discourse structure of modern human sciences, criticizing the Traditional Philosophy of Transcendental Consciousness and Subjectivism of Western Philosophy. Michel Foucault, who held that the subject is just a product of discourse constitution, destroyed the concept of creative subjects through the revelation of the underlying rules constituting the possible conditions of thought. And he also regarded the development of thought as a series of epistemological ruptures, which disrupted the logic of the identity that determined modern thought and made possible the reflections on others.
\end{abstract}

KEYWORD: Foucault; subject; knowledge; discourse; episteme.

Michel Foucault is the most famous and the most active and most influential postmodern characters, is the most important after Sartre, contemporary French thinker. Main problem is an important topic in Foucault thought, more accurately, criticism of the concept of various rational subject, the rational subject concept dominated the western thought since the enlightenment. All the writings of Foucault are oriented in the break deep thoughts of this kind of self-reflection, the rule of unified and rational subject, for thinking and existence of the "other" radical way clear the turf. Foucault do, is to oppose and explode as the pillar of the western cultural tradition capital of western rational. Foucault on the subject of metaphysics and the principle of subjectivity, criticism and deconstruction, and he is using one of the important strategy by highlighting the status of "the other". Foucault's "the other" exists in the common to ignore even despise but quite important the edge of the field and humble, and in Foucault's archeology and genealogy research in different periods, the concrete connotation of the concept of "the other" are also different, but the Foucault's "the other" generally refers to the exclusion of traditional rational body outside, in the traditional metaphysics of rationality, identity and truth outside of those things. Foucault's purpose of the study is through illuminates the "edge" to highlight, highlighting "the other", highlight the phenomenon such as crazy, disease, crime and sexual ways to eliminate the need for the traditional western "center", to criticize and negate the traditional metaphysics, reveal the true essence of the principle of subjectivity.

Foucault humanities archaeology in his times, the modern history of the humanities and its discourse structure and rules of specific research and analysis, and fundamentally dispelled over decisive condition of the formation of the contemporary knowledge of anthropology subject of fog, criticizing the traditional western philosophy more than two hundred years since Descartes, Kant's transcendental philosophy and main body consciousness. Foucault think the source of the subject is not the meaning, it in fact just words in the composition of product, so does not exist as a concept meaning only the origin of the body. Foucault through deep rules, reveals the possibility of a thought condition destroyed the concept of creative subject, and the development of the western thought as a series of epistemological rupture, which disrupted the ideas of modern decision identity logic, made it possible to send to his thinking.

\section{THE MAIN BODY OF THE BIRTH AND DEATH}

And things in the word ", Foucault, points out that with the rational from the Renaissance to the modern concept of continuous development on the contrary, western thought in fact is divided into three distinct, the understanding of the discontinuous zone, that is to say, in every period have different type "know". "Understanding" is a kind of inevitable, nameless 
and unconscious thought forms, it is a kind of innate knowledge, defining experience overall in a specific period, a field of qualified in the field of the mode of existence of the object. Its possibility in words at the time of the given conditions, is a set of prior the composition of the rules. Type in Foucault's view, knowledge is not stationary, but the historic, intermittent, and tend to be suddenly know type conversion, arbitrary, formed the epistemological rupture, from a kind of knowledge to another kind of knowledge transformation is not described as a gradual process, but is described as a sudden and complete rupture. "All the differences, all of the scattering, all of the discontinuity, shrinkage in the cone, so that only a point of identity formation, do not touch of the same form, but the form has a power displayed in the self and becomes his." [1]

Foucault started with the Renaissance the scope of the major common grammar and linguistic analysis, natural history and biology, and wealth and the history of economics. In this range, he thinks happened twice fracture, the knowledge from the Renaissance know the classical knowledge into modern understanding. Foucault understanding of these three type and type of two faults are described in detail. One is the understanding of the Renaissance, the Renaissance of the people in accordance with the things between each other "similar" to the order of things and the combination of all kinds of thinking. Is similar to the Renaissance, the characteristics of the knowledge type "similarity" restriction, dominates the westerners' understanding of language and cognition. "Until the late 16th century, the similarity in the knowledge of western culture has been founder effect. It was similarity that mainly lead the text annotation and interpretation; it was similarity that form the symbol of operation, make the human to know many things visible and invisible, and guides the art representation things." [2] in the early 17 th century, the similarity is no longer regarded as a source of knowledge, and regarded it as causes of errors. Roughly in the middle of the 17 th century, the western ideas, and to clarify the fundamental rupture type during the Renaissance, the western understanding of classical thought structure type is dominated, dominate the classical knowledge system is a kind of "knowledge representation model", the same with the difference principle replaced the similarity principle, knowledge is the order of appearance. Renaissance three yuan of language understanding was replaced by the binary system of transparent relationship between classical period, the classical symbol representation that the object of the contents of it directly. The end of the 18th century in the early 19th century, classical know fracture type, type is converted into a modern understanding. People began to think about things in a new method and its mutual relations, after the break, the space is no longer the identity and difference of space of knowledge, and be composed of discrete organic structure space, so the modern knowledge type can be called "organic structure" type, with the principle of work and continuous become modern knowledge organization.

Foucault, points out that only by the end of the 18th century happened after fracture of epistemology, common syntax, wealth analysis and natural history to literature, economics and biology, "people" as the object of knowledge only. Representation at this time is no longer simply equated with ideas, people can question the origin of the image, image has become the object of knowledge, people then. Place on the basis of the decline in the representation of the three science require experience as the main body of them already, and become the object of them. In classical times, about grammar or wealth system research, need only can through to the content of the sequence of representation, without the humanities, so people within the classical knowledge does not exist. Only since the early 19th century, lost it once had in the classical knowledge discourse role of knowledge, and the experience of the law of world power, the talent, the humanities to produce. Due to the modern philosophy of the limitation of people experience analysis as the people of the infinite nature of the prior analysis, so the modern philosophy into the "sleeping" anthropology, knowledge is considered to be subject to transcendental subject, in the ultimate sense transcendental subject is regarded as the "source" of knowledge, but also determines the identity of the knowledge, unity and continuity.

Foucault through the analysis of his humanities archaeology, points out that real knowledge is not by pure reason as "transcendental subject" or pure consciousness, but by "know", "discourse configuration rule". Foucault said: "the person is a recent invention, a has yet to have 200 people, a simple creases in the knowledge of human mind once found a new form of human knowledge, people will disappear." [3] in the end, Foucault come to the conclusion that the "dead", Foucault through archaeological analysis of the European culture since the 16th century, draws the conclusion that "man is one of the recent idea.... as we thought the archaeology can easily show, people is a recent invention. And is close to its destination. If the arrangement will disappear like occurs, if through some possibilities we can feeling the events, but don't know the form and hope it tipped over, like the end of the 18th century classical thought on the basis of experience, so people can properly bet: people will be erased, like the sand by the sea of a face." [4]

In short, in Foucault view: not main dominant knowledge production, but the practice of the knowledge production of the main body, people never exist to exist to disappear, in the western of 
the knowledge of type is fundamental arrangement of the result of the change. Know type led to the fracture of knowledge in the same field, which broke the story of the continuity of knowledge in the same field, Foucault through the analysis of knowledge type and described the history of knowledge has become a history dominated by the principle of discourse structure, thus reveals the essence of the subject, for thinking about the problem of knowledge provides a way of anthropology.

\section{THE MAIN BODY--THE PRODUCT OF WORDS}

In the archaeology of knowledge, Foucault think discourse domain has the priority, in this kind of priority, it determines the speech event. That is to say, the field of social - institutions only within a special kind of discourse form is expressed, it can get a sense or a unified. Archaeology adhere to the main body position in the discourse constitute the internal dispersion, this to be able to personally take provides the scope of the subject position of a form of description. Foucault wrote: "we should not state the main idea is to express is the author of the same. Whether from the material or from the function, they are not the same. In fact, the body of the presentation is not sure of a sentence is spoken or written, reasons of this phenomenon according to the statement or starting point... the location of the subject is a sure and blank. It can be filled by different individuals." [5] can be seen from in this passage as before of discourse is the author of the source concept or principal concept is being questioned.

Archaeology method abandoned a supreme body as all knowledge source of ideas. Foucault said, to impart knowledge to the main body of the origin of the word before the privilege, it ignored the fact that the subject itself - "its position, its function, its cognitive ability" - in fact, which is decided by the rules and these rules are beyond the scope of transcendental consciousness. According to the archaeology, is not individual give meaning to words, but the "discourse" provides a large number of individuals can occupy "main body position. Foucault said: "the formation of a word is not fully occupied its object, statements, the concepts such as various kinds of system has the right to provide all possible space, it is basically a blank, and the gap is caused by the formation of the strategy choices of discourse system." [6] Foucault through the subject as a statement of the location of the mercurial, realized the decentralization of the subject, the subjective intention of the subject rejection is out from the description of the statement. The subject, he argues, is a statement derived can be dominated by different people in the position. Main body of the discontinuity of the decentralization and history are interrelated. The history of "continuous is an associated body, based on main body function is essential" [7], that is to say, to advocate the continuity of history, the progress and even free general history of historicism is presupposes that the foundation stone of the transcendental subject and tectonic action, continuous, uninterrupted history and consciousness of sovereignty is inalienable. Thus, Foucault unearthed the possibility of a history of intermittent, thus inhibiting the prior structure and foundation of the subject, the expand of the intellectual history and ideology history is not transcendental subject, is anonymous, no identity. According to Foucault's view, the core problem of contemporary thought is not thinking about his ability: "we fear in our own mind thinking about other people in the age of" [8], because order is an established knowledge by a single value of "identity" dominated by logic.

Foucault through archaeological analysis revealed that preceded the language exists and is all about the origin of the body of the concept is a kind of produced in the illusion of structure rules, this kind of structure rules govern the "discourse". As the main body of the function of the discourse, is determined by the overall structure of the relationship between discourse practice, that is, not subject dominant discourse, but the subject of discourse generated. Foucault's archaeology through rules, the construction of thought and limit thought words broke the dominated the logical order of the identity, so that the emergence of a new way of thinking in a space.

\section{REFERENCES}

[1] Michel Foucault. Word and things Weimin Mo translation. Shanghai: the joint publishing company LTD., Shanghai 2002. P. 430

[2] Michel Foucault. Word and things Weimin Mo translation. Shanghai: the joint publishing company LTD., Shanghai 2002. On page 23.

[3] Michel Foucault. Word and things Weimin Mo translation. Shanghai: the joint publishing company LTD., Shanghai 2002. Page 13.

[4] Michel Foucault. Word and things Weimin Mo translation of Shanghai: the joint publishing company LTD., Shanghai 2002. P. 506.

[5] Michel Foucault. Knowledge archaeology Xie Jiang, horse on translation. Beijing: life, reading, new knowledge, 1998. Pp. 119-118.

[6] Michel Foucault. Knowledge archaeology Xie Jiang, horse on translation. Beijing: life, reading, new knowledge, 1998. P. 83.

[7] Michel Foucault. Knowledge archaeology Xie Jiang, horse on translation. Beijing: life, reading, new knowledge the joint publishing company LTD., 1998. The page 15.

[8] Michel Foucault. Knowledge archaeology Xie Jiang, horse on translation. Beijing: life, reading, new knowledge, 1998. On page 14. 